\title{
Determination of Trace Amounts of Palladium in Water Samples by Graphite Furnace Atomic Absorption Spectrometry after Dispersive Liquid-Liquid Microextraction
}

\author{
Mohammad Reza Jamali, ${ }^{1}$ Yaghoub Assadi, ${ }^{2}$ and Reyhaneh Rahnama Kozani ${ }^{1}$ \\ ${ }^{1}$ Department of Chemistry, Payame Noor University, Tehran 19395-3697, Iran \\ ${ }^{2}$ Quality Control Department, Daana Pharmaceutical Company, Tabriz 501575-5181, Iran \\ Correspondence should be addressed to Mohammad Reza Jamali; mr_jamali@ymail.com
}

Received 21 June 2012; Accepted 8 October 2012

Academic Editor: Serife Tokalioglu

Copyright (C) 2013 Mohammad Reza Jamali et al. This is an open access article distributed under the Creative Commons Attribution License, which permits unrestricted use, distribution, and reproduction in any medium, provided the original work is properly cited.

A simple, rapid, and powerful microextraction technique was used for determination of palladium (II) ion in water samples using dispersive liquid-liquid microextraction (DLLME) followed by graphite furnace atomic absorption spectrometry (GF AAS). The different variables affecting the complexation and extraction conditions such as extraction and disperser solvent type, extraction time, $\mathrm{pH}$, and concentration of chelating agent were optimized. Under the optimum conditions, the calibration graph was linear in the ranges of $0.05-1 \mu \mathrm{g} \mathrm{L}^{-1}$ with detection limit of $0.02 \mu \mathrm{g} \mathrm{L}^{-1}$. The precision (RSD \%) for ten replicate determination at $0.2 \mu \mathrm{g} \mathrm{L}$ of palladium was better than $3.5 \%$ and the enrichment factor 166.5 was obtained from only $5.0 \mathrm{~mL}$ of sample. Under the presence of foreign ions, no significant interference was observed. Finally, accuracy and application of the method were estimated by using test samples of natural waters spiked with different amounts of palladium.

\section{Introduction}

Palladium has been used in different areas of science and technology including agents, brazing alloys, petroleum, electrical industries, and catalytic chemical reactions. The metal may enter the environment and interact with complexing materials, such as humic substances. Palladium has no biological role and all palladium compounds should be regarded as highly toxic and carcinogenic. Thus, because of its increasing use, on one hand, the toxicity of palladium (II) compounds to mammals, fish, and higher plants, on the other hand [1-4], the separation, concentration, and determination of palladium are of interest in environmental analysis.

The complexity of matrix and low concentration levels of palladium in industrials $\left(\mu \mathrm{g} \mathrm{g}^{-1}\right)$ and environmental $\left(\mathrm{ng} \mathrm{g}^{-1}\right)$ make direct measurements of this metal difficult. Therefore, the application of highly sensitive techniques, such as ICPMS [5-7] and GF AAS [8, 9], coupled with a separation and enrichment procedure is necessary.
Liquid-liquid extraction has been widely used for separation of platinum metals [10-12]. Because of some disadvantages of solvent extraction methods such as the use large volume of expensive and toxic organic solvents, emulsion formation, and low sensitivity much interest has been recently focused in repairing conventional solvent extraction methods for isolating environmental pollutants with other separation/preconcentration methods such as solid phase extraction [13-15] and cloud point extraction [16]. In concretely, homogeneous liquid-liquid extraction $[17,18]$ and single-drop microextraction $[19,20]$ have been used for extraction and determination of some of the metal ions.

In previous research, we demonstrated a novel microextraction technique which was named dispersive liquidliquid microextraction (DLLME) that was used for the extraction and determination of polycyclic aromatic hydrocarbons (PAHs) [21], organophosphorus pesticides (OPPs) [22], chlorobenzenes [23], and Trihalomethanes [24] by gas chromatography and metal ions by atomic absorption spectrometry $[25,26]$. This is a modified solvent extraction 
TABLE 1: Graphite furnace temperature for determination of palladium.

\begin{tabular}{lcccc}
\hline Step & $\begin{array}{c}\text { Temperature } \\
\left({ }^{\circ} \mathrm{C}\right)\end{array}$ & $\begin{array}{c}\text { Ramp } \\
\text { time }(\mathrm{s})\end{array}$ & $\begin{array}{c}\text { Hold } \\
\text { time }(\mathrm{s})\end{array}$ & $\begin{array}{c}\text { Argon gas flow } \\
\left(\mathrm{mL} \mathrm{min}^{-1}\right)\end{array}$ \\
\hline Drying & 150 & 20 & 10 & 100 \\
Pyrolysis & 1000 & 3 & 10 & 250 \\
Atomization & 2700 & 0 & 2 & 0 \\
Cleaning & 2800 & 0 & 2 & 1000 \\
\hline
\end{tabular}

method and its acceptor-to-donor phase ratio is greatly reduced comparing to other extraction methods. In this method, the appropriate mixture of extraction solvent and disperser solvent is rapidly injected into aqueous samples containing analytes by syringe. Thereby, cloudy solution is formed. In fact, the cloudy state is because of the formation of fine droplets of extraction solvent which has been dispersed among the sample solution. Then, this cloudy solution was centrifuged and the fine droplets were settled in the bottom of conical test tubes. The determination of analytes in settled phase can be performed by instrumental analysis. In this extraction method, any component originally present in the solution that interacts with the fine droplets of extraction solvent directly or after previous derivatization reaction can be extracted from the initial solution and concentrated in the small volume of the settled phase. The advantages of DLLME method are simplicity of operation, rapidity, low cost, high recovery, and enrichment factor.

The purpose of this paper is to demonstrate the feasibility of DLLME combined with GF AAS for determination of palladium (II) ion in water samples.

\section{Experimental}

2.1. Instrumentation. The experiments were performed using a Shimadzu atomic absorption spectrometer (AA 6300G) with a graphite furnace atomizer (GFA-EX7i). A palladium hollow cathode lamp, operated at a current of $10 \mathrm{~mA}$ and a wavelength of $247.6 \mathrm{~nm}$ with a spectral band pass of $0.7 \mathrm{~nm}$ was used. Pyrolytic graphite-coated graphite tubes were purchased from Shimadzu.

The sample injection volume was $20 \mu \mathrm{L}$ in all experiments. The instrumental parameters and temperature program for the graphite atomizer are listed in Table 1. Argon 99.999\% purity (Air Product, West Sussex, UK) was used as purge gas.

Separation of phases was assisted using a centrifuge (centurion scientific model: K 240R). The $\mathrm{pH}$ values were measured with a Metrohm pH-meter (model: 713) supplied with a glass-combined electrode.

2.2. Reagents and Solutions. All reagents used were of analytical grade. All solutions were prepared using doubly distilled deionized water. Stock solution of palladium $\left(1000.0 \mathrm{mg} \mathrm{L}^{-1}\right)$ was prepared by dissolving appropriate amounts of metallic $\mathrm{Pd}$ in aqua regia. Working solutions were prepared from the stock solution by serial dilutions with doubly distilled deionized water.

Chloroform, methanol, and ethanol were of analyticalgrade from Merck (Darmstadt, Germany). $2 \times 10^{-3} \mathrm{~mol} \mathrm{~L}^{-1}$ solution of $4,4^{\prime}$-Bis (dimethylamino) thiobenzophenone, Thio-Michler's ketone (TMK), (Merck, Darmstadt, Germany) was prepared by dissolving appropriate amount of TMK in chloroform. This solution was kept in a dark place at room temperature.

A stock standard acetic acid/sodium acetate buffer solution (0.1 $\left.\mathrm{mol} \mathrm{L}^{-1}, \mathrm{pH} 3.0\right)$ was prepared by dissolving an appropriate amount of sodium acetate in doubly distilled deionized water and neutralizing to $\mathrm{pH} 3.0$ with hydrochloride acid.

The pipettes and vessels used for trace analysis were kept in $10 \%$ nitric acid for at least $24 \mathrm{~h}$ and subsequently washed four times with deionized water before use.

2.3. Dispersive Liquid-Liquid Microextraction Procedure. A $5.0 \mathrm{~mL}$ of doubly-distilled water was placed in a $10 \mathrm{~mL}$ screw cap glass test tube with conic bottom and spiked at levels of $0.05-1 \mu \mathrm{g} \mathrm{L}^{-1}$ of palladium and the $\mathrm{pH}$ of solution was adjusted by adding acetic acid/sodium acetate buffer solution ( $\mathrm{pH} 3.0$ ). Then the mixture of $500 \mu \mathrm{L}$ of methanol (as disperser solvent) and $70 \mu \mathrm{L}$ of chloroform (as extraction solvent) containing $1.0 \times 10^{-3} \mathrm{~mol} \mathrm{~L}^{-1}$ of Thio-Michler's ketone (as chelating agent) was injected rapidly into a sample solution by using $1.00-\mathrm{mL}$ syringe, and the mixture was gently shaken. A cloudy solution was formed in a test tube. In this step, palladium ions were extracted into the fine droplets of chloroform. The mixture was then centrifuged for $2 \mathrm{~min}$ at $5000 \mathrm{rpm}$. After this process, the dispersed fine droplets of chloroform were settled in the bottom of conical test tube $(30 \pm 1 \mu \mathrm{L})$. A $20 \mu \mathrm{L}$ of this settled phase was removed using a $25-\mu \mathrm{L}$ microsyringe and injected into graphite furnace atomic absorption spectrometer for analysis.

\section{Results and Discussion}

In order to obtain a high recovery and enrichment factor, the effect of different parameters affecting the complexation and extraction conditions such as $\mathrm{pH}$, concentration of buffer and chelating agent, kind of extraction and disperser solvent and volume of them, extraction time, and salt addition were investigated and optimized. In order to study the explained parameters, extraction recovery and enrichment factor have been calculated by the following equations:

$$
\mathrm{EF}=\frac{C_{\text {sed }}}{C_{0}}
$$

where $\mathrm{EF}, \mathrm{C}_{\text {sed }}$, and $\mathrm{C}_{0}$ are the enrichment factor, concentration of analyte in sedimented phase and initial concentration of analyte in aqueous sample, respectively,

$$
\mathrm{ER} \%=\frac{C_{\text {sed }} \times V_{\text {sed }}}{C_{0} \times V_{\mathrm{aq}}} \times 100=\mathrm{EF} \times \frac{V_{\mathrm{sed}}}{V_{\mathrm{aq}}} \times 100,
$$




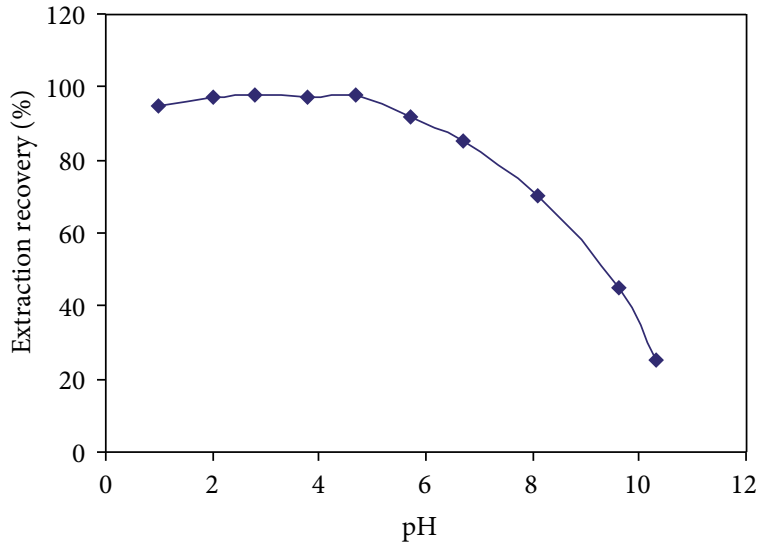

FIGURE 1: Effect of $\mathrm{pH}$ on extraction recovery of palladium obtained from DLLME. Extraction conditions: water sample volume, $5.0 \mathrm{~mL}$; disperser solvent (methanol) volume, $500 \mu \mathrm{L}$; extraction solvent $\left(\mathrm{CHCl}_{3}\right), 70 \mu \mathrm{L}$; TMK concentration, $1.0 \times 10^{-3} \mathrm{~mol} \mathrm{~L}^{-1}$; concentration of palladium, $0.4 \mu \mathrm{g} \mathrm{L}^{-1}$.

where ER\%, $V_{\text {sed }}$, and $V_{\text {aq }}$ are the extraction recovery, volume of sedimented phase and volume of aqueous sample, respectively.

These parameters are known except $C_{\text {sed }}$. Calculation of $C_{\text {sed }}$ was done by direct injection of standard solution of palladium-TMK complex in chloroform with concentration in the range of $10-150 \mu \mathrm{g} \mathrm{L}^{-1}$.

3.1. Effect of $p H$. The separation of metal ions by dispersive liquid-liquid microextraction involves prior formation of a complex with sufficient hydrophobicity to be extracted into the small volume of sedimented phase; thus obtaining the desired preconcentration. $\mathrm{pH}$ plays a unique role on metalchelate formation and subsequent extraction. The influences of the $\mathrm{pH}$ on the quantitative recovery values of palladium ions were investigated at the $\mathrm{pH}$ range of 1.0-10.0 using $\mathrm{HCl}$ and $\mathrm{NaOH}$ while other parameters were kept constant. The results illustrated in Figure 1 reveal that the extraction recovery is nearly constant in the $\mathrm{pH}$ range of $1-5$. Hence, the $\mathrm{pH}$ of 3.0 was chosen for further extraction.

3.2. Effect of TMK Concentration. Dispersive liquid-liquid microextraction of $2.0 \mathrm{ng}$ of palladium using TMK from $5.0 \mathrm{~mL}$ of the sample solutions was conducted by varying the concentration of TMK in chloroform $(70 \mu \mathrm{L})$. The extraction recovery for $\mathrm{Pd}$ (II) as a function of the concentration of chelating agent is shown in Figure 2. As can be seen, the recovery increases up to a TMK concentration of 5.0 $\times 10^{-4} \mathrm{~mol} \mathrm{~L}^{-1}$ and reaches near quantitative extraction efficiency. A concentration of $1.0 \times 10^{-3} \mathrm{~mol} \mathrm{~L}^{-1}$ of TMK in chloroform was chosen to account for other extractable species that might potentially interfere with the assaying of Pd (II).

3.3. Effect of Type and Volume of Extraction Solvent. Careful attention should be paid to the selection of the extraction

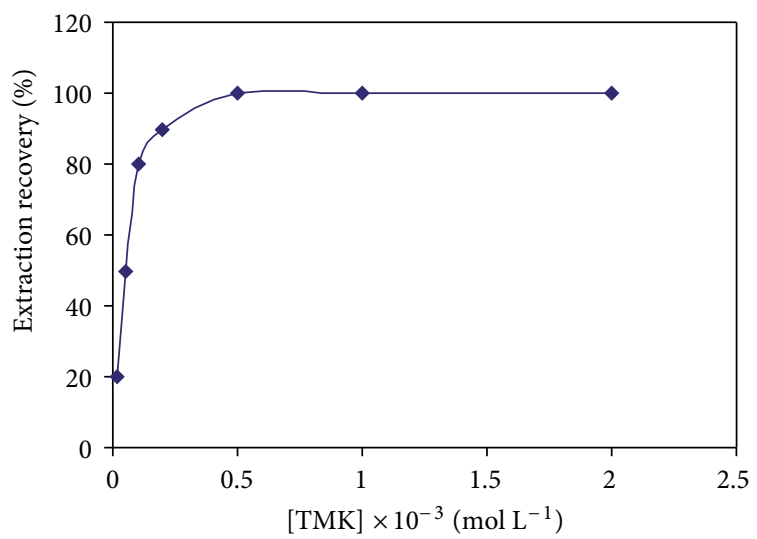

FIgURE 2: Effect of TMK on extraction recovery of palladium obtained from DLLME. Extraction conditions: water sample volume, $5.0 \mathrm{~mL}$; disperser solvent (methanol) volume, $500 \mu \mathrm{L}$; extraction solvent $\left(\mathrm{CHCl}_{3}\right), 70 \mu \mathrm{L}$; concentration of palladium, $0.4 \mu \mathrm{g} \mathrm{L}^{-1}$; $\mathrm{pH}=3.0$.

solvent. It should have higher density rather than water, extraction capability of interested compounds and low solubility in water. Chloroform, carbon tetrachloride, tetrachloroethylene, carbon disulfide, and chlorobenzene were compared in the extraction of palladium. A series of sample solution were studied by using $500 \mu \mathrm{L}$ methanol containing different volumes of extraction solvent to achieve $30 \mu \mathrm{L}$ volume of sedimented phase. Thereby, 70, 50, 40, 35, and $40 \mu \mathrm{L}$ of chloroform, carbon disulfide, carbon tetrachloride, tetrachloroethylene, and chlorobenzene were used, respectively. The results revealed that chloroform has the highest extraction efficiency (98.5\%) in comparison with carbon disulfide (92.5\%), carbon tetrachloride (92.0\%), tetrachloroethylene (70.0\%), and chlorobenzene (81.0\%). Hence, chloroform was chosen as extraction solvent.

To examine the effect of the extraction solvent volume, solutions containing different volumes of chloroform were subjected to the same DLLME procedures. The experimental conditions were fixed and include the use of $500 \mu \mathrm{L}$ methanol containing different volumes of chloroform $(60,70,80,90,100,110$, and $120 \mu \mathrm{L})$. By increasing the volume of chloroform from 60 to $120 \mu \mathrm{L}$, the volume of settled phase increases from 20 to $80 \mu \mathrm{L}$. Figure 3 shows the curve of enrichment factor and extraction recovery versus volume of the extraction solvent (chloroform).

According to Figure 3, enrichment factor decreases with increasing the volume of chloroform, because of the volume of the settled phase increases. Subsequently, at low volume of the extraction solvent high enrichment factor was obtained. Thereby, the gain in sensitivity was achieved by using $60 \mu \mathrm{L}$ of chloroform. In this state the volume of settled phase was $20 \mu \mathrm{L}$. Since, complete removal of this volume by syringe for injection into graphite furnace atomic absorption spectrometer is difficult, $70 \mu \mathrm{L}$ of chloroform $(30 \mu \mathrm{L}$ settled phase) was selected as optimum volume of extraction solvent. 


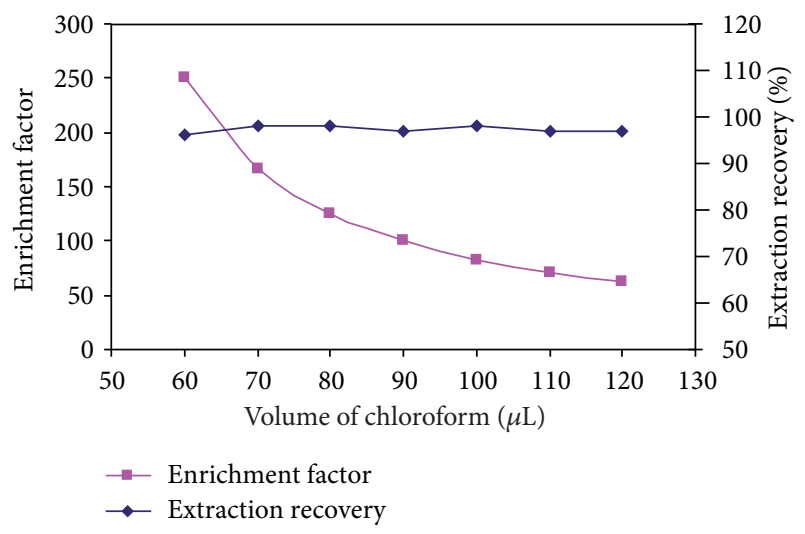

FIGURE 3: Effect of the volume of extraction solvent $\left(\mathrm{CHCl}_{3}\right)$ on the enrichment factor and extraction recovery of palladium obtained from DLLME. Extraction conditions: water sample volume, $5.0 \mathrm{~mL}$; disperser solvent (methanol) volume, $500 \mu \mathrm{L}$; TMK concentration, $1.0 \times 10^{-3} \mathrm{~mol} \mathrm{~L}^{-1}$; concentration of palladium, $0.4 \mu \mathrm{g} \mathrm{L}^{-1}$; $\mathrm{pH}=3.0$.

\subsection{Effect of Type and Volume of Disperser Solvent. The} main criterion for selection of the disperser solvent is its miscibility in the extraction solvent and aqueous sample. For this purpose, different solvents such as acetone, acetonitrile, tetrahydrofuran, and methanol were tested. A series of sample solutions were studied by using $500 \mu \mathrm{L}$ of each disperser solvent containing $70 \mu \mathrm{L}$ of chloroform (extraction solvent). The results showed extraction recovery was the best when methanol was used. Thus, methanol was selected as a disperser solvent.

Investigation of the effect of different volume of methanol (disperser solvent) on the extraction recovery would be very rough. Since, variation of the volume of methanol makes change in the volume of settled phase at constant volume of chloroform (extraction solvent). Thereby, to avoid this matter and in order to achieve a constant volume of settled phase $(30 \mu \mathrm{L})$ the volume of methanol and chloroform were changed, simultaneously. The experimental conditions were fixed and include the use of different volumes of methanol $250,500,750,1000$, and $1500 \mu \mathrm{L}$ containing $65,70,75,80$, and $100 \mu \mathrm{L}$ of chloroform, respectively. Under these conditions, the volume of the sedimented phase was constant $(30 \pm$ $1 \mu \mathrm{L}$ ). The results showed that there was no considerable variation on extraction recovery between 250 and $750 \mu \mathrm{L}$ of methanol and the extraction recovery was high and then decreased by increasing the volume of methanol. It is clear that by increasing the volume of methanol, the solubility of complex in water increases. Therefore, the extraction recovery decreases. Thus, $500 \mu \mathrm{L}$ of methanol was selected as optimum volume in order to achieve better and more stable cloudy solution.

3.5. Effect of Extraction Time. Extraction time is one of the most important factors in the most of extraction procedure. In DLLME, extraction time is defined as interval time between injection mixture of disperser and extraction solvent, and starting to centrifuge. The effect of extraction

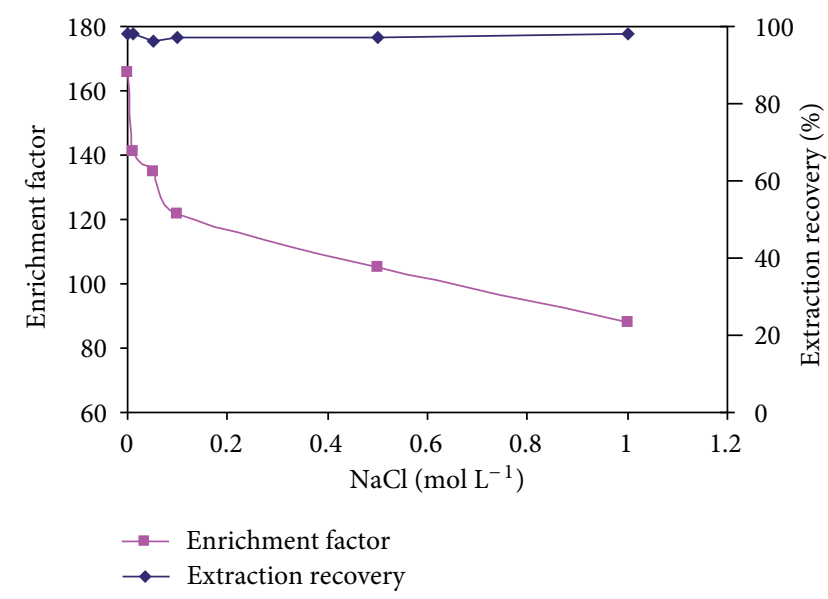

FIgURE 4: Effect of the salt on the enrichment factor and extraction recovery of palladium obtained from DLLME. Extraction conditions: water sample volume, $5.0 \mathrm{~mL}$; disperser solvent (methanol) volume, $500 \mu \mathrm{L}$; extraction solvent $\left(\mathrm{CHCl}_{3}\right), 70 \mu \mathrm{L}$; TMK concentration, $1.0 \times 10^{-3} \mathrm{~mol} \mathrm{~L}^{-1}$; concentration of palladium, $0.4 \mu \mathrm{g} \mathrm{L}^{-1}$; $\mathrm{pH}=3.0$.

time was examined in the range of $0-45 \mathrm{~min}$ with constant experimental conditions. The results showed that the extraction recovery increased by increasing extraction time up to $1 \mathrm{~min}$ and after that remained constant. Thus, $1 \mathrm{~min}$ was used for extraction time in the subsequent experiments.

3.6. Effect of Salt. For investigating the influence of the ionic strength on performance of DLLME, various experiments were performed by adding different amount of $\mathrm{NaCl}$ (0.0-1.0 $\left.\mathrm{mol} \mathrm{L}^{-1}\right)$. Other experimental conditions were kept constant. The results showed (Figure 4) that the enrichment factor decreased by increasing the ionic strength. This decreasing in enrichment factor is because by increasing the ionic strength (from 0.0 to $1.0 \mathrm{~mol} \mathrm{~L}^{-1}$ ), solubility of extraction solvent in aqueous phase decreases and the volume of sedimented phase increases. According to these results, ionic strength has no appreciable effect upon extraction efficiency up to $1.0 \mathrm{~mol} \mathrm{~L}^{-1}$ of $\mathrm{NaCl}$. These observations showed the possibility of using this method to separation of palladium from highly saline solutions.

3.7. Effect of Coexisting Ions. The effects of common coexisting ions in natural water samples on the recovery of palladium were studied. In these experiments, $5.0 \mathrm{~mL}$ of solutions containing $0.2 \mu \mathrm{g} \mathrm{L}^{-1}$ of palladium and various amounts of interfering ions were treated according to the recommended procedure. An ion was considered to interfere when its presence produced a variation of more than $5 \%$ in the extraction recovery of the sample. The results showed that, in excess of 10000 -fold $\mathrm{Cl}^{-}, \mathrm{Br}^{-}, \mathrm{SO}_{4}{ }^{2-}, \mathrm{Li}^{+}, \mathrm{K}^{+}, \mathrm{Na}^{+}$, $\mathrm{Ca}^{2+}, \mathrm{Mg}^{2+}, \mathrm{Ba}^{2+}$, and $\mathrm{Sr}^{2+}$ and $5000-$ fold $\mathrm{Ag}^{+}, \mathrm{Co}^{2+}, \mathrm{Cu}^{2+}$, $\mathrm{Cd}^{2+}, \mathrm{Ni}^{2+}, \mathrm{Zn}^{2+}, \mathrm{Mn}^{2+}, \mathrm{Pb}^{2+}, \mathrm{Al}^{3+}, \mathrm{Cr}^{3+}, \mathrm{Fe}^{3+}$, and $\mathrm{Pt}(\mathrm{IV})$ ions had no significant interferences on the extraction and determination of palladium. 
TABLE 2: Analytical characteristics of proposed method.

\begin{tabular}{lc}
\hline Parameter & Analytical feature \\
\hline Linear range $\left(\mu \mathrm{g} \mathrm{L}^{-1}\right)$ & $0.05-1.0$ \\
Limit of detection $\left(\mu \mathrm{g} \mathrm{L}^{-1}\right)(n=10)$ & 0.02 \\
Repeatability $\left(\mathrm{RSD}^{\mathrm{a}}, \%\right)(n=10)$ & 3.5 \\
Enrichment factor & 166.5
\end{tabular}

${ }^{\mathrm{a}} \mathrm{Pd}(\mathrm{II})$ concentration was $0.2 \mu \mathrm{g} \mathrm{L} \mathrm{L}^{-1}$ for which RSD was obtained.

${ }^{\mathrm{b}}$ Concentration factor is the volume ratio $\left(V_{a} / V_{s}\right)$ of the aqueous phase $\left(V_{a}\right)$ and volume of sedimented phase $\left(V_{s}\right)$.

3.8. Figures of Merit. Table 2 summarizes the analytical characteristics of the optimized method, including linear range, limit of detection, repeatability, and enrichment factor. The calibration graph was linear in the ranges of $0.05-1.0 \mu \mathrm{g} \mathrm{L}^{-1}$ of palladium. The limit of detection, defined as $C_{L}=3 S_{B} / m$ (where $C_{L}, S_{B}$, and $m$ are the limit of detection, standard deviation of the blank and slope of the calibration graph, resp.), was $0.02 \mu \mathrm{g} \mathrm{L}^{-1}$. The relative standard deviation (RSD) for ten replicate measurements of $0.2 \mu \mathrm{g} \mathrm{L}^{-1} \mathrm{Pd}$ (II) was $3.5 \%$.

The enrichment factor (the volume ratio $\left(V_{a} / V_{s}\right)$ of the aqueous phase $\left(V_{a}=5000 \mu \mathrm{L}\right)$ and volume of sedimented phase $\left.\left(V_{s}=30 \mu \mathrm{L}\right)\right)$ was 166.5 .

3.9. Application to Samples. The proposed DLLME-GF AAS methodology was applied to the determination of $\mathrm{Pd}$ in several water samples. Water samples (i.e., tap water, sea water, river water and mineral water) were filtered using a $0.45 \mu \mathrm{m}$ pore size membrane filter to remove suspended particulate matter and aliquots of water $(5.0 \mathrm{~mL})$ were subjected to DLLME. According to the results, the concentration of palladium in analyzed water samples was below the LOD of the method. Moreover the robustness of the proposed method was checked by performing recovery test on a synthetic sample (no certified reference material was available). Each type of water was spiked with variable amounts of Pd (II) to assess matrix effects. The results are shown in Table 3. The relative recoveries of palladium from mentioned water samples at various spiking levels were between 85.0 and $99.0 \%$. These results which demonstrated matrices of these water samples, in our present context, had little effect on DLLME of palladium.

\section{Conclusion}

Dispersive liquid-liquid microextraction combined with graphite furnace atomic absorption spectrometry allows tackling the determination of palladium in natural waters in a simple way. The method is simple, rapid and economical. High preconcentration factor was obtained easily through this method and a detection limit at sub $\mu \mathrm{gL}^{-1}$ level was achieved with only $5.0 \mathrm{~mL}$ of sample. In this method preparation time as well as consumption of toxic organic solvents was minimized without affecting the sensitivity of the method.
TABLE 3: Determination of Pd(II) in different water samples.

\begin{tabular}{|c|c|c|c|c|}
\hline Sample & $\begin{array}{c}\mathrm{Pd}^{2+} \text { spiked } \\
\left(\mu \mathrm{g} \mathrm{L}^{-1}\right)\end{array}$ & $\begin{array}{c}\mathrm{Pd}^{2+} \text { detected } \\
\left(\mu \mathrm{g} \mathrm{L}^{-1}\right)\end{array}$ & $\begin{array}{c}\mathrm{RSD}^{\mathrm{g}} \\
(\%)\end{array}$ & $\begin{array}{c}\text { Recovery } \\
(\%)\end{array}$ \\
\hline \multirow{3}{*}{ Tap water ${ }^{\mathrm{a}}$} & 0.000 & n.d. ${ }^{f}$ & & - \\
\hline & 0.100 & 0.098 & 3.6 & 98.0 \\
\hline & 0.200 & 0.198 & 3.5 & 99.0 \\
\hline \multirow{3}{*}{ Sea water ${ }^{b}$} & 0.000 & n.d. & & - \\
\hline & 0.100 & 0.085 & 3.7 & 85.0 \\
\hline & 0.200 & 0.172 & 3.8 & 86.0 \\
\hline \multirow{3}{*}{ River water $^{c}$} & 0.000 & n.d. & & - \\
\hline & 0.100 & 0.092 & 3.6 & 92.0 \\
\hline & 0.200 & 0.188 & 3.5 & 94.0 \\
\hline \multirow{3}{*}{$\begin{array}{l}\text { Mineral } \\
\text { water }^{\mathrm{d}}\end{array}$} & 0.000 & n.d. & & - \\
\hline & 0.100 & 0.097 & 3.4 & 97.0 \\
\hline & 0.200 & 0.192 & 3.5 & 96.0 \\
\hline \multirow{2}{*}{$\begin{array}{l}\text { Synthetic } \\
\text { sample }^{e}\end{array}$} & 0.100 & 0.095 & 3.8 & 95.0 \\
\hline & 0.200 & 0.193 & 3.3 & 96.5 \\
\hline
\end{tabular}

From drinking water system of Tehran, Iran.

${ }^{\mathrm{b}}$ Caspian sea water, Iran.

${ }^{c}$ Ziarat River, Gorgan, Iran.

${ }^{\mathrm{d}}$ From Abali mineral water, Tehran, Iran.

${ }^{\mathrm{e}} \mathrm{Cu}^{2+}, \mathrm{Co}^{2+}, \mathrm{Cd}^{2+}, \mathrm{Fe}^{3+}, \mathrm{Ag}^{+}, \mathrm{Cr}^{3+}, 500 \mu \mathrm{g} \mathrm{L}{ }^{-1}$ of each cation.

${ }^{\mathrm{f}}$ Not detected.

${ }^{\mathrm{g}} \mathrm{RSD}$ of three replicate experiments.

\section{Acknowledgment}

The authors thank the research council at the University of Tehran and Iran University of Science and Technology for financial support.

\section{References}

[1] A. Kabata-Pendias and A. B. Mukherjee, Trace Elements from Soil to Human, Springer, Berlin, Germany, 2007.

[2] K. Machida, M. Enyo, G. Adachi, and J. Shiokawa, "Synthesis and electrocatalytic properties of rare earth platinum or palladium bronzes," Bulletin of the Chemical Society of Japan, vol. 60, pp. 411-413, 1987.

[3] S. A Cotton, Chemistry of Precious Metals, Blackie Academic and Professional, Chapman \& Hall, London, UK, 1997.

[4] S. D. Lee, Biochemical Aspects of Environmental Pollutants, Ann Arbor Science, Ann Arbor, Mi, USA, 1980.

[5] I. Jarvis, M. M. Totland, and K. E. Jarvis, "Assessment of Dowex 1-X8-based anion-exchange procedures for the separation and determination of ruthenium, rhodium, palladium, iridium, platinum and gold in geological samples by inductively coupled plasma mass spectrometry," Analyst, vol. 122, no. 1, pp. 19-26, 1997.

[6] M. Moldovan, M. M. Gomez, and M. A. Palacios, "On-line preconcentration of palladium on alumina microcolumns and determination in urban waters by inductively coupled plasma mass spectrometry," Analytica Chimica Acta, vol. 478, no. 2, pp. 209-217, 2003.

[7] J. Enzweiler, P. J. Potts, and K. E. Jarvis, "Determination of platinum, palladium, ruthenium and iridium in geological 
samples by isotope dilution inductively coupled plasma mass spectrometry using a sodium peroxide fusion and tellurium coprecipitation," The Analyst, vol. 120, no. 5, pp. 1391-1396, 1995.

[8] A. Levai, A. Lasztity, K. Zih-Perenyi, and Z. Horvath, "Graphite furnace atomic absorption spectrometry determination and online preconcentration of palladium," Microchemical Journal, vol. 58, no. 3, pp. 272-280, 1998.

[9] J. Komarek, P. Krasensky, J. Balcar, and P. Ehulka, "Determination of palladium and platinum by electrothermal atomic absorption spectrometry after deposition on a graphite tube," Spectrochimica Acta B, vol. 54, pp. 739-743, 1999.

[10] Z. Marczenko, Separaction and Spectrophotometric Determination of Elements, John willey \& Sons, New York, NY, USA, 1986.

[11] S. V. Bandekar and P. M. Dhadke, "Solvent extraction separation of platinum (IV) and palladium (II) by 2-ethylhexyl phosphonic acid mono-2-ethylhexyl ester (PC-88A)," Separation and Purification Technology, vol. 13, pp. 129-135, 1998.

[12] T. N. Lokhande, M. A. Anuse, and M. B. Chavan, "Liquidliquid extraction of palladium(II) with N-n-octylaniline from hydrochloric acid media," Talanta, vol. 46, no. 1, pp. 163-169, 1998.

[13] S. Zhang, Q. Pu, P. Liu, Q. Sun, and Z. Su, "Synthesis of amidinothioureido-silica gel and its application to flame atomic absorption spectrometric determination of silver, gold and palladium with on-line preconcentration and separation," Analytica Chimica Acta, vol. 452, no. 2, pp. 223-230, 2002.

[14] K. Farhadi and G. Teimouri, "Flame atomic absorption determination of palladium in solutions after preconcentration using octadecyl silica membrane disks modified by thioridazine. $\mathrm{HCl}$," Talanta, vol. 65, no. 4, pp. 925-929, 2005.

[15] Ş. Tokalığlu, T. Oymak, and Ş. Kartal, "Determination of palladium in various samples by atomic absorption spectrometry after preconcentration with dimethylglyoxime on silica gel," Analytica Chimica Acta, vol. 511, no. 2, pp. 255-260, 2004.

[16] D. L. G. Borges, M. A. M. S. D. Velga, V. L. A. Frescura, B. Welz, and A. J. Curtius, "Cloud-point extraction for the determination of $\mathrm{Cd}, \mathrm{Pb}$ and $\mathrm{Pd}$ in blood by electrothermal atomic absorption spectrometry, using Ir or Ru as permanent modifiers," Journal of Analytical Atomic Spectrometry, vol. 18, no. 5, pp. 501-507, 2003.

[17] S. Igarashi, A. Takahashi, Y. Ueki, and H. Yamaguchi, "Homogeneous liquid-liquid extraction followed by X-ray fluorescence spectrometry of a microdroplet on filter-paper for the simultaneous determination of small amounts of metals," Analyst, vol. 125, no. 5, pp. 797-798, 2000.

[18] A. R. Ghiasvand, S. Shadabi, E. Mohagheghzadeh, and P. Hashemi, "Homogeneous liquid-liquid extraction method for the selective separation and preconcentration of ultra trace molybdenum," Talanta, vol. 66, no. 4, pp. 912-916, 2005.

[19] S. Fragueiro, I. Lavilla, and C. Bendicho, "Hydride generationheadspace single-drop microextraction-electrothermal atomic absorption spectrometry method for determination of selenium in waters after photoassisted prereduction," Talanta, vol. 68, no. 4, pp. 1096-1101, 2006.

[20] S. Fragueiro, I. Lavilla, and C. Bendicho, "Headspace sequestration of arsine onto a $\mathrm{Pd}(\mathrm{II})$-containing aqueous drop as a preconcentration method for electrothermal atomic absorption spectrometry," Spectrochimica Acta B, vol. 59, no. 6, pp. 851-855, 2004.
[21] M. Rezaee, Y. Assadi, M. R. Milani Hosseini, E. Aghaee, F. Ahmadi, and S. Berijani, "Determination of organic compounds in water using dispersive liquid-liquid microextraction," Journal of Chromatography A, vol. 1116, no. 1-2, pp. 1-9, 2006.

[22] S. Berijani, Y. Assadi, M. Anbia, M. R. Milani Hosseini, and E. Aghaee, "Dispersive liquid-liquid microextraction combined with gas chromatography-flame photometric detection. Very simple, rapid and sensitive method for the determination of organophosphorus pesticides in water," Journal of Chromatography A, vol. 1123, no. 1, pp. 1-9, 2006.

[23] R. R. Kozani, Y. Assadi, F. Shemirani, M. R. M. Hosseini, and M. R. Jamali, "Part-per-trillion determination of chlorobenzenes in water using dispersive liquid-liquid microextraction combined gas chromatography-electron capture detection," Talanta, vol. 72, no. 2, pp. 387-393, 2007.

[24] R. Rahnama Kozani, Y. Assadi, F. Shemirani, M. R. Milani Hosseini, and M. R. Jamali, "Determination of trihalomethanes in drinking water by dispersive liquid-liquid microextraction then gas chromatography with electron-capture detection," Chromatographia, vol. 66, no. 1-2, pp. 81-86, 2007.

[25] E. Zeini Jahromi, A. Bidari, Y. Assadi, M. R. Milani Hosseini, and M. R. Jamali, "Dispersive liquid-liquid microextraction combined with graphite furnace atomic absorption spectrometry. Ultra trace determination of cadmium in water samples," Analytica Chimica Acta, vol. 585, no. 2, pp. 305-311, 2007.

[26] A. Bidari, E. Zeini Jahromi, Y. Assadi, and M. R. Milani Hosseini, "Monitoring of selenium in water samples using dispersive liquid-liquid microextraction followed by iridiummodified tube graphite furnace atomic absorption spectrometry," Microchemical Journal, vol. 87, no. 1, pp. 6-12, 2007. 

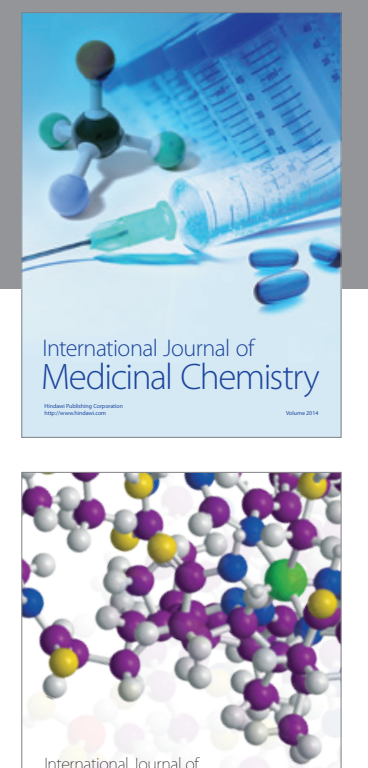

\section{Carbohydrate} Chemistry

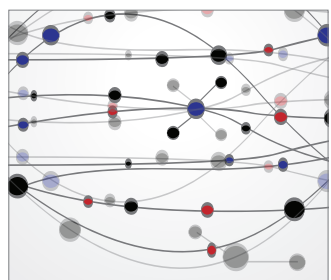

The Scientific World Journal
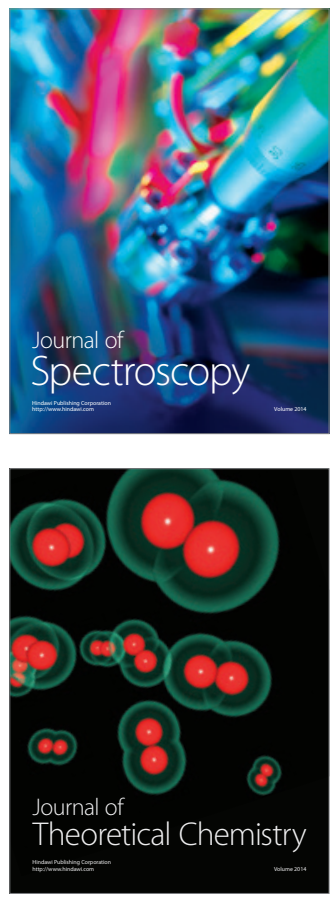
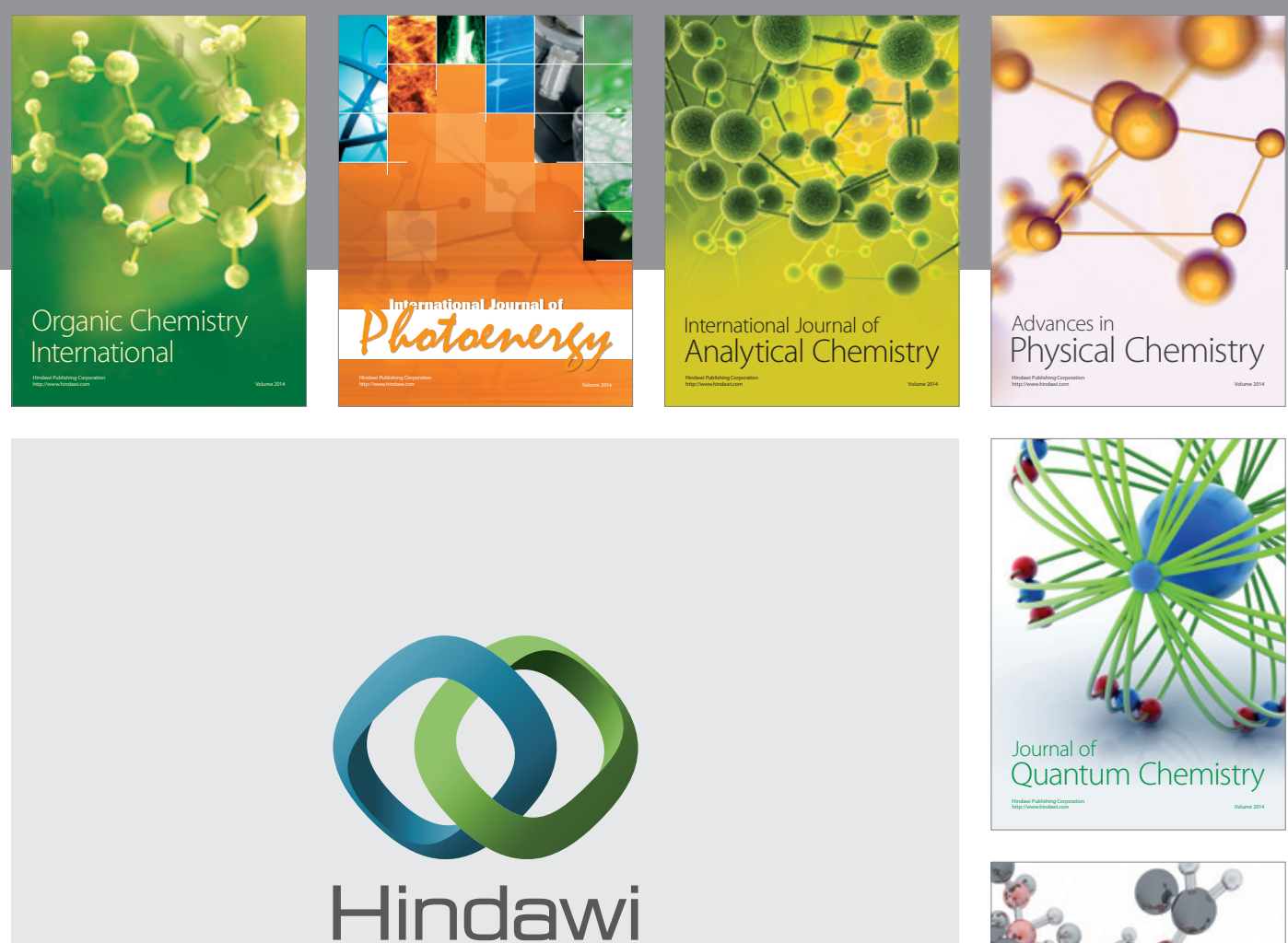

Submit your manuscripts at

http://www.hindawi.com

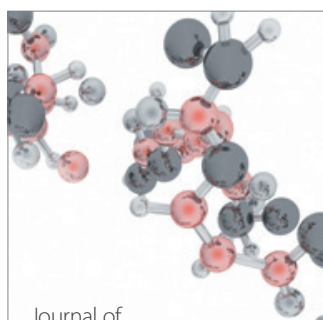

Analytical Methods

in Chemistry

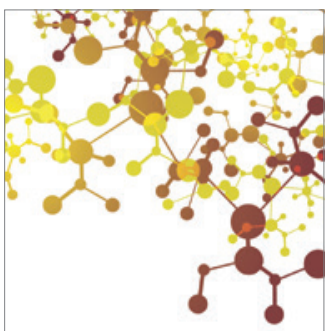

Journal of

Applied Chemistry

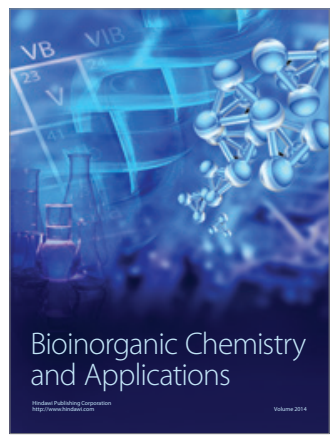

Inorganic Chemistry
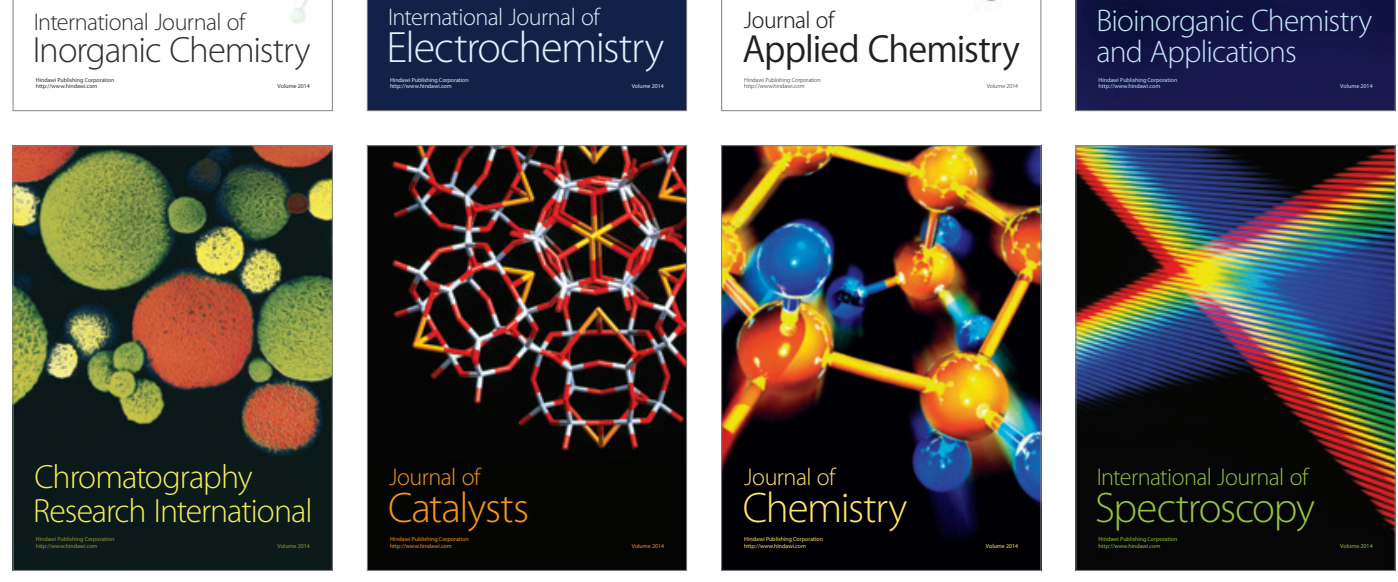